DOI: $10.1002 / \mathrm{dhm} .201800255$

Article type: Full paper

\title{
Tissue Compatibility of SN-38-Loaded Anticancer Nanofiber Matrices
}

Alejandro Manzanares, Camilo A. Restrepo-Perdomo, Gaia Botteri, Helena CastilloEcija, Guillem Pascual-Pasto, Francesc Cano, Laura Garcia-Alvarez, Carles Monterrubio, Bonaventura Ruiz, Manuel Vazquez-Carrera, Mariona Suñol, Jaume Mora, Jose A. Tornero, Alejandro Sosnik, Angel M. Carcaboso*

Dr Alejandro Manzanares, Dr Camilo A. Restrepo-Perdomo, Dr Gaia Botteri, Helena Castillo-Ecija, Dr Guillem Pascual-Pasto, Dr Carles Monterrubio, Dr Manuel VazquezCarrera, Dr Mariona Suñol, Dr Jaume Mora, Dr Angel M. Carcaboso*

Institut de Recerca Sant Joan de Déu, Barcelona 08950, Spain

*E-mail (AM Carcaboso): amontero@fsjd.org

Dr Alejandro Manzanares, Dr Carles Monterrubio, Dr Gaia Botteri, Helena CastilloEcija, Dr Guillem Pascual-Pasto, Dr Jaume Mora, Dr Angel M. Carcaboso Department of Pediatric Hematology and Oncology, Hospital Sant Joan de Deu, Barcelona 08950, Spain

Dr Alejandro Manzanares

Department of Pediatric Surgery, Hospital Universitari Germans Trias i Pujol, Barcelona, Spain

Dr Camilo A. Restrepo-Perdomo, Dr Mariona Suñol

Department of Pathology, Hospital Sant Joan de Deu, Barcelona, Spain

Francesc Cano, Dr Jose A. Tornero

Institut de Investigació Textil i Cooperació Industrial de Terrassa (INTEXTER), Universitat Politecnica de Catalunya, Barcelona, Spain

Laura Garcia-Alvarez, Dr Bonaventura Ruiz

Department of Laboratory Medicine, Hospital Sant Joan de Deu, Barcelona, Spain

Dr Carles Monterrubio, Human Oncology \& Pathogenesis Program, Memorial Sloan Kettering Cancer Center, New York, NY 10065, USA

Dr Manuel Vazquez-Carrera

Institut de Biomedicina de la Universitat de Barcelona (IBUB), Pharmacology Unit, Department of Pharmacology, Toxicology and Therapeutic Chemistry, Faculty of Pharmacy and Food Sciences, University of Barcelona, Barcelona, Spain

Dr Manuel Vazquez-Carrera

Centro de Investigación Biomédica en Red de Diabetes y Enfermedades Metabólicas Asociadas (CIBERDEM), Instituto de Salud Carlos III, Barcelona, Spain

Dr Alejandro Sosnik 


\section{WILEY-VCH}

Laboratory of Pharmaceutical Nanomaterials Science, Department of Materials Science and Engineering, Technion-Israel Institute of Technology, Technion City, Haifa, Israel

Camilo A. Restrepo-Perdomo, Gaia Botteri and Helena Castillo-Ecija contributed equally to this work.

Keywords: surgery of pediatric neoplasms, drug delivery systems, SN-38, nanofibers, tissue compatibility 


\title{
WILEY-VCH
}

\begin{abstract}
Delivery of chemotherapy in the surgical bed has shown preclinical activity to control cancer progression upon subtotal resection of pediatric solid tumors, but whether this new treatment is safe for tumor-adjacent healthy tissues remains unknown. Here Wistar rats were used to study the anatomic and functional impact of electrospun nanofiber matrices eluting SN-38 -a potent chemotherapeutic agent- on several body sites where pediatric tumors such as neuroblastoma, Ewing sarcoma and rhabdomyosarcoma arise. We placed blank and SN-38-loaded matrices embracing the femoral neurovascular bundle or in direct contact with abdominal viscera (liver, kidney, urinary bladder, intestine and uterus). Foreign body tissue reaction to the implants was observed though no histologic damage in any tissue/organ. Skin healing was normal. Tissue reaction was similar for SN-38-loaded and blank matrices, with the exception of the hepatic capsule that was thicker for the former although within the limits consistent with mild foreign body reaction. Tissue and organ function was completely conserved after local treatments, as assessed by the rotarod test (forelimb function), hematologic tests (liver and renal function) and control of clinical signs. Overall, these findings support the clinical translation of SN-38 loaded nanofiber matrices to improve local control strategies of surgically resected tumors.
\end{abstract}




\section{WILEY-VCH}

\section{Introduction}

Surgery, radiation therapy (RT) and systemic chemotherapy are intensively combined as treatment plan for most pediatric solid tumors. ${ }^{[1]}$ One of the goals of this treatment strategy is to minimize the risk of cancer recurrence in the primary location while minimizing systemic exposure and off-target toxicity such as secondary tumors and infertility upon systemic chemotherapy or RT, or functional sequelae due to aggressive surgery. ${ }^{[2]}$

Children cancer survivors are a group of patients in which long-term and chronic adverse effects should be especially avoided ${ }^{[3]}$. Thus, the development of innovative treatments with better safety/activity profiles than the currently available is an urgent need. In line with this, Intra-Operative Electron Beam Radiation Therapy (IOERT) reached clinical practice in pediatric oncology to minimize the radiation of tissues surrounding a resected tumor. ${ }^{[4]}$ IOERT is performed during the surgical procedure to apply controlled RT doses immediately after resection in the surgical bed that contains macroscopic or microscopic tumor rests. ${ }^{[5]}$ However, IOERT requires expensive infrastructure and is not available in most health institutions around the world. In this scenario, other alternatives including Local Drug Delivery Systems (LDDS) are currently undergoing intensive preclinical investigation to address the unmet medical need of a safer and more efficacious local control of solid tumors by means of maximizing local drug distribution, while minimizing systemic exposure. ${ }^{[6]}$ To pave the way to clinical trials, LDDS are made of biocompatible and FDA-approved polymers such as poly(lactic acid) (PLA), poly(lactic-co-glycolic acid) (PLGA) and poly(epsilon-caprolactone) (PCL) and may carry potent anticancer drugs that are not suitable for systemic administration due to their poor aqueous solubility and/or physicochemical instability. ${ }^{[6 a, 6 e]}$ Recently we have studied PLA nanofiber matrices 
loaded with microcrystals of the potent anticancer agent SN-38 (10-hydroxycamptothecin) to control the relapse of surgically removed pediatric tumors. ${ }^{[6 e]} \mathrm{SN}-38$, an inhibitor of topoisomerase I, is 1000 fold more active against malignancies than its prodrug irinotecan (camptothecin-11). ${ }^{[7]}$ However, the clinical use of SN-38 is impeded by the extremely low solubility in water of its lactone form. ${ }^{[8]}$ Thus, the improvement of SN-38 delivery to target tissues by means of chemical or formulation modifications has been the focus of several studies during recent years. ${ }^{[6 a, 9]} \mathrm{SN}-38$-loaded nanofiber matrices improve local control of extracranial pediatric solid tumors including neuroblastoma and Ewing sarcoma patient-derived xenografts, achieving minimal drug exposure in the circulating blood. ${ }^{[6 e]}$ The clinical application of these matrices would involve their insertion into the surgical bed to contact with unresectable tumor rests. ${ }^{[6 e}$, ${ }^{10]}$ Using microdialysis as sampling method in restrained animals we determined that SN-38 achieves high concentrations (up to $2.5 \mu \mathrm{M}$ ) in the virtual space surrounding the matrices. ${ }^{[6 e]}$ However, whether such high local exposure is toxic for non-tumoral tissues surrounding the drug-eluting matrix remains not fully characterized. This is especially important because pediatric tumor rests are usually adjacent, infiltrating or wrapping around vital organs including blood vessels, nerves and viscera, whose long-term function should be conserved.

In this work we used an immunocompetent rat model to simulate the clinical conditions of pediatric patients undergoing tumor resection and we evaluated the local toxicity of local SN-38-loaded nanofiber matrices on the femoral neurovascular bundle and vital organs such as liver, kidney and bladder. Overall, our preclinical findings showed the high safety and tolerability of SN-38 loaded nanofiber matrices and reaffirm their potential as a drug delivery platform to control the relapse of surgically resected tumors. 


\section{WILEY-VCH}

\section{Results}

\subsection{Drug activity and in vitro characterization of the matrices}

We described previously the potent activity of SN-38 in a variety of human pediatric cancer cell lines, either as free drug or loaded in nanofiber matrices. ${ }^{[6]]}$ In this study, we evaluated the cytotoxic activity of the drug in murine hepatocytes (H2.35) as a model of nontumor cells. We used Ewing sarcoma (SK-ES-1) and rhabdomyosarcoma (Rh30) cell lines as reference tumor models. First, we calculated the concentrations of free SN38 inhibiting $50 \%$ of cell proliferation (IC50). IC50 values ( $\pm 95 \%$ confidence intervals) for SK-ES-1 and Rh30 were $0.72(0.64-0.81)$ and 2.8 (1.8-5.1) nM, respectively. Hepatocytes were more than 10-fold less sensitive to the antiproliferative effect of SN38, with an IC50 of 50 (30-114) nM (Figure 1A). The cytotoxic effect of SN-38 on cell monolayers, measured as the release of lactate dehydrogenase (LDH), was also more pronounced in tumor cells, compared to hepatocytes that were sensitive to SN-38 only at concentrations higher than $200 \mathrm{nM}$ (Figure 1B).

SN-38-loaded PLA/PLGA nanofiber matrices (local-SN-38) were produced by electrospinning, containing $18 \mu \mathrm{g} \mathrm{SN}-38 / \mathrm{cm}^{2}$, as previously described. ${ }^{[6 \mathrm{e}]}$ Matrices without SN-38 (local-blank) were also manufactured. The matrices were $150 \mu \mathrm{m}$ thick. SN-38-loaded matrices released completely the drug upon $24 \mathrm{~h}$ incubation in medium containing 2-hydroxypropyl-beta-cyclodextrin (HPBCD; 10\% w/v) as solubilizer (Figure 1C). The drug remaining in the matrices was less than $0.1 \%$ at the end of the study. Thus, the release profile of SN-38 from the PLA/PLGA nanofiber matrices in vitro in solubilizing medium was comparable with the previously reported in PLA-only nanofibers. ${ }^{[6]}$ Then, the activity $0.25 \mathrm{~cm}^{2}$ matrices was evaluated in cell monolayers covering the surface $\left(1.9 \mathrm{~cm}^{2}\right)$ of culture wells. In this experiment we observed that the LDDS was potently active to inhibit pediatric cancer cells, while hepatocytes conserved 
1D).

A
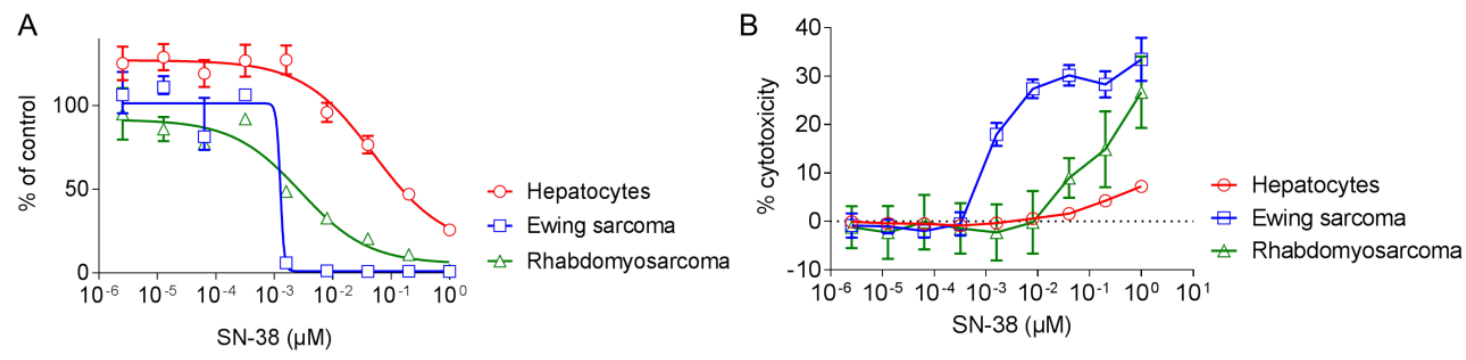

C

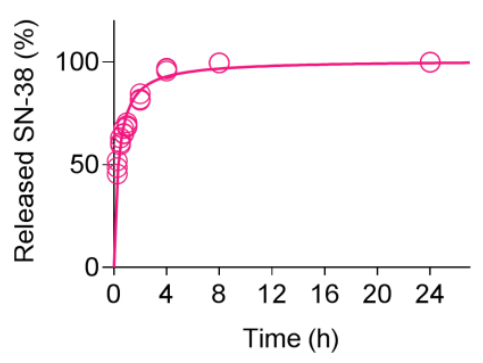

$\mathrm{D}$

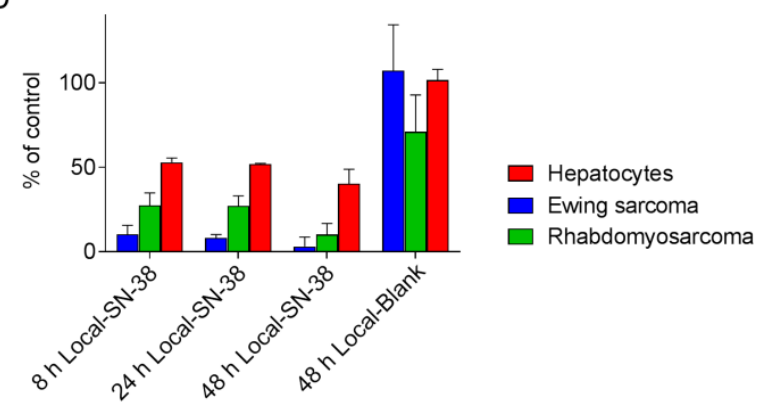

Figure 1. SN-38 activity and in vitro characterization of the matrices. A.

Antiproliferative activity (MTS assay) of SN-38 against murine hepatocytes (H2.35), human Ewing sarcoma (SK-ES-1) and rhabdomyosarcoma (Rh30) cell lines. Values are expressed as \% of MTS signal of control untreated cells that were considered $100 \%$. Means and SD from 6 replicates at each SN-38 concentration are shown. B. Cytotoxic activity (LDH assay) of SN-38. LDH signal values from treated cells were corrected by subtracting the spontaneous LDH release by untreated control cells and are expressed as $\%$ of the maximum cytotoxic activity achieved in cells treated with lysis buffer. Means and SD from 6 replicates at each SN-38 concentration are shown. C. In vitro cumulative release of $\mathrm{SN}$-38-loaded matrices in phosphate buffered saline containing $10 \%$ HPBCD as solubilizer. Individual data from three replicates and the best-fitting curve using the Michaelis Menten model in Graphpad software are shown. D. Activity of SN-38 matrices (MTS assay) against cell culture monolayers upon exposures ranging 8-48 h. Blank matrices did not show significant antiproliferative activity.

\subsection{Surgical models}

The main goal of our work was to simulate in a suitable animal model the clinical conditions in which pediatric cancer patients would receive LDDS matrices. To assess the local biocompatibility of the matrices in different target tissues and organs and their 


\section{WILEY-VCH}

function, three different experimental models were designed in Wistar rats (Figure 2). Matrices were cut in $2 \mathrm{~cm}^{2}(2 \times 1 \mathrm{~cm})$ rectangles for the application in the animals.

\subsubsection{Neurovascular model}

The aim of this model was to evaluate the effect of local-SN-38 matrices on the neurovascular bundles and skin scarring/healing. The right femoral neurovascular bundle of the rat was exposed and dissected in one centimeter length through a skin incision on the medial part of the right thigh. Then, the treatment was applied wrapping around the bundle.

\subsubsection{Hepatorenal model}

To study the toxicity of local-SN-38 on the liver and kidney surfaces, first left nephrectomy was performed by lumbotomy. Then, right lumbotomy was performed to expose the kidney and the lateral aspect of the liver. The treatment was applied and fastened to the upper and lateral surface of the kidney.

\subsubsection{Bladder model}

To address local urinary bladder, intestinal and uterine biocompatibility, lower median laparotomy was performed and the bladder, uterus and rectum were exposed. Then, the LDDS was applied on the posterior surface of the bladder, anterior and upper surface of the uterine corpus and anterior wall of the rectum, fastened with two sutures to the uterus and one to the rectum wall. 


\section{WILEY-VCH}
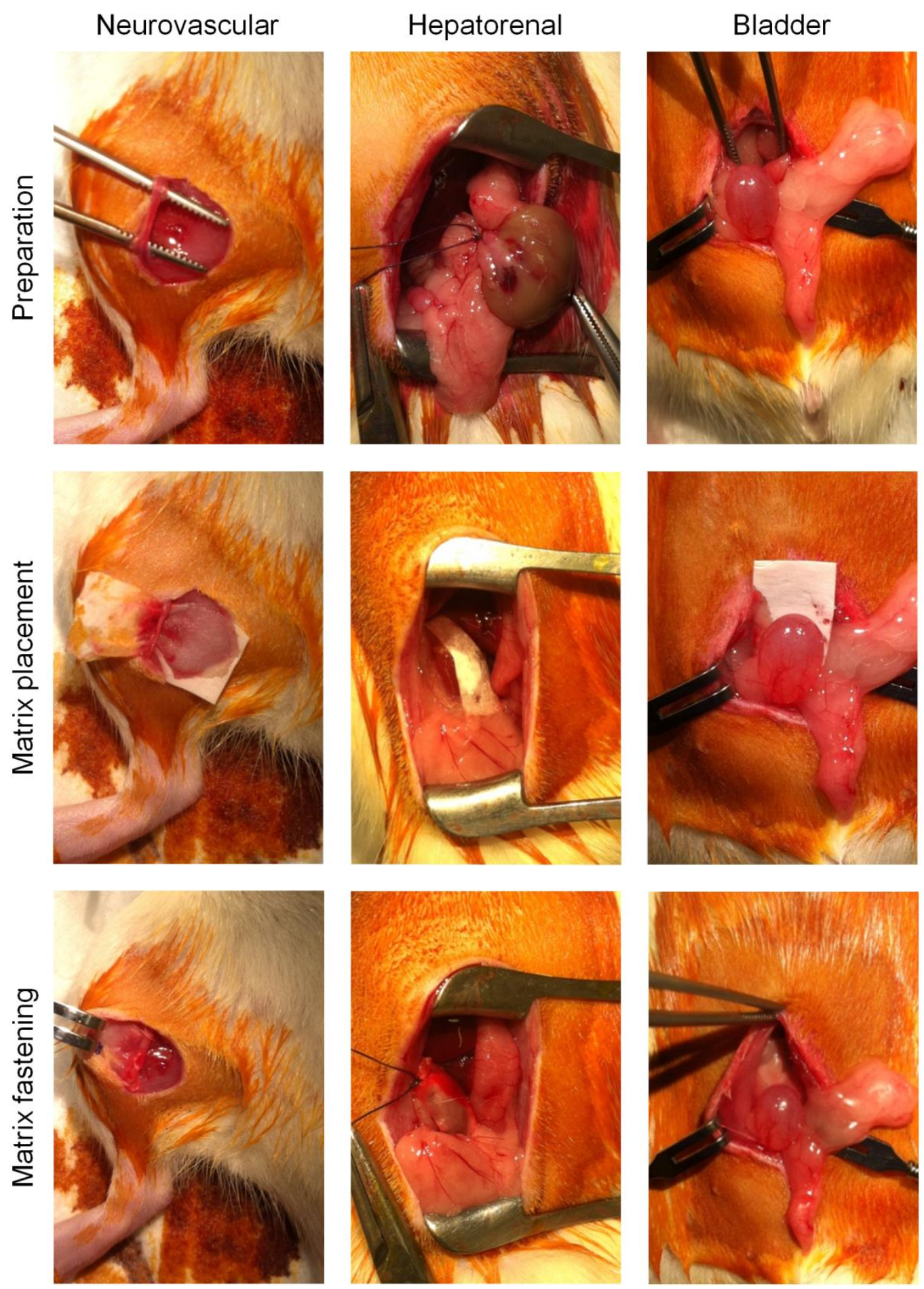

Figure 2. Surgical procedure showing the preparation and dissection of the target structures, the placement of the $2 \mathrm{~cm}^{2}$ nanofiber matrices and their fastening with sutures (not visible in the bladder model due to fatty tissue interposition). Manufactured matrices were resistant to traction, flexible and adaptable to curved surfaces. Upon moistening with the body fluids of the rats they became more friable. Thus, sutures were carefully applied to avoid damaging the matrices during their fixation to the surfaces of the treated tissues. 


\section{WILEY-VCH}

A total of 18 animals were allocated to each experimental model and randomly assigned to one of the following treatment groups: (a) single insertion of $2 \mathrm{~cm}^{2}(2 \times 1 \mathrm{~cm})$ of a PLA/PLGA nanofiber matrix loaded with $36 \mu \mathrm{g}$ of SN-38 (Local-SN-38 Group); (b) single insertion of $2 \mathrm{~cm}^{2}(2 \times 1 \mathrm{~cm})$ of a PLA/PLGA nanofiber matrix (Local-Blank Group); and (c) single surgery performed in the same conditions of the previous treatment groups, though without the administration of nanofiber matrices (Sham Group). To evaluate the short- (acute) and long-term (chronic) effect of the local treatment, we collected samples at two time points. Thus, half of the animals in each group were euthanized 16 days after the surgery (acute samples) and the remaining half was euthanized 70 days post-surgery (chronic samples). At both tissue sampling times the matrices appeared rigid and adhered to tissues in direct contact.

\subsection{Histopathology}

We did not observe any treatment-related histologic alterations in normal tissues including vessels, nerves and muscle (Figure 3), liver and kidney (Figure 4) or uterus, bladder and rectum (Figure 5). The nanofiber matrices could be identified as empty spaces in the formalin-fixed paraffin-embedded (FFPE) blocks, due to the solubilization of the polymer during the processing of the paraffin. They were identified in the neurovascular bundle (Figure 3), in contact with the renal and liver surfaces (Figure 4) or the bladder, uterine and rectal surfaces (Figure 5). 


\section{WILEY-VCH}
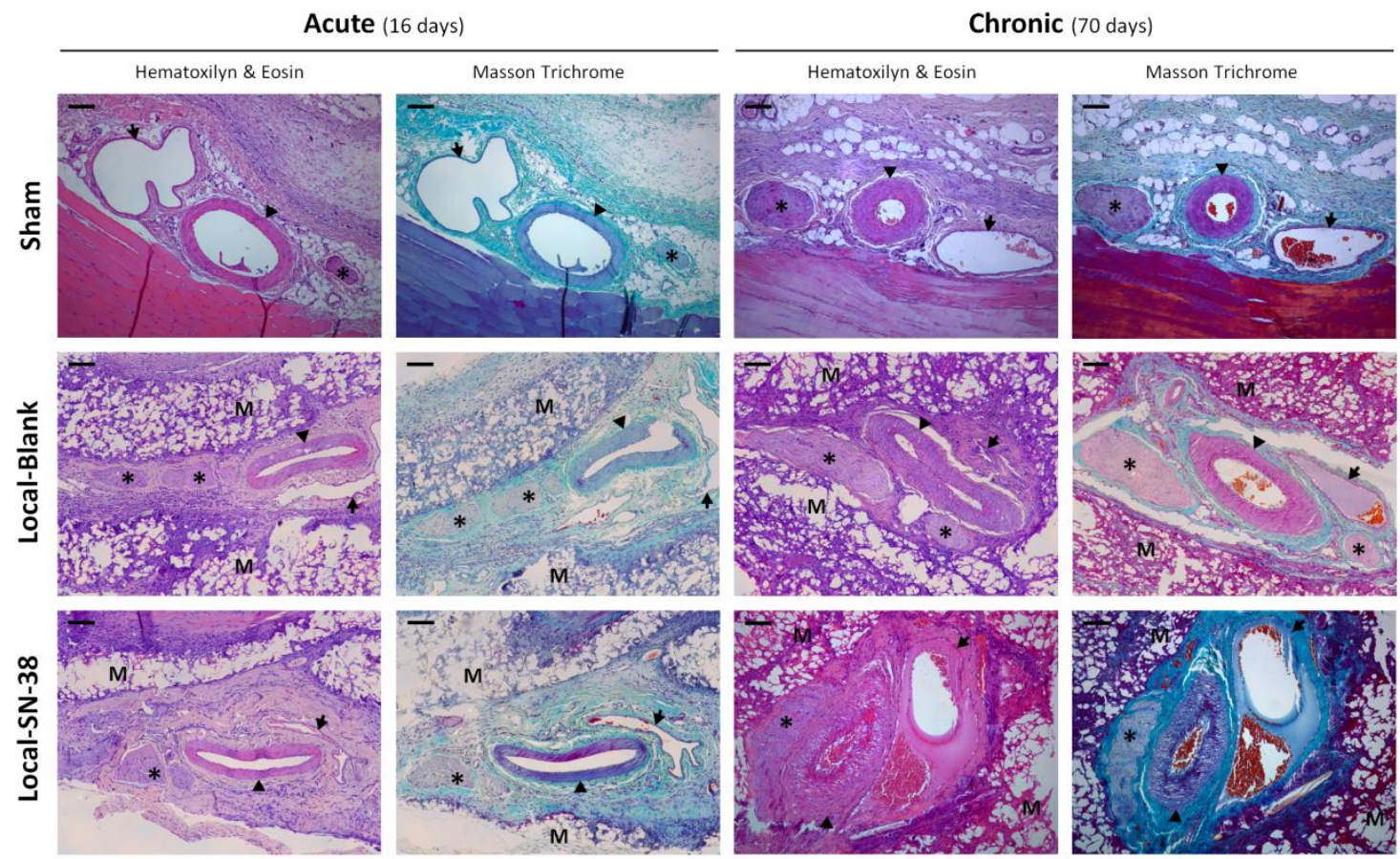

Figure 3. Histology of the Neurovascular model upon acute (16 day) or chronic (70 days) exposure to local treatments. (M): matrix; (*): nerves; arrow heads: arteries; arrows: veins. Representative pictures are shown. Scale bars are $100 \mu \mathrm{m}$.
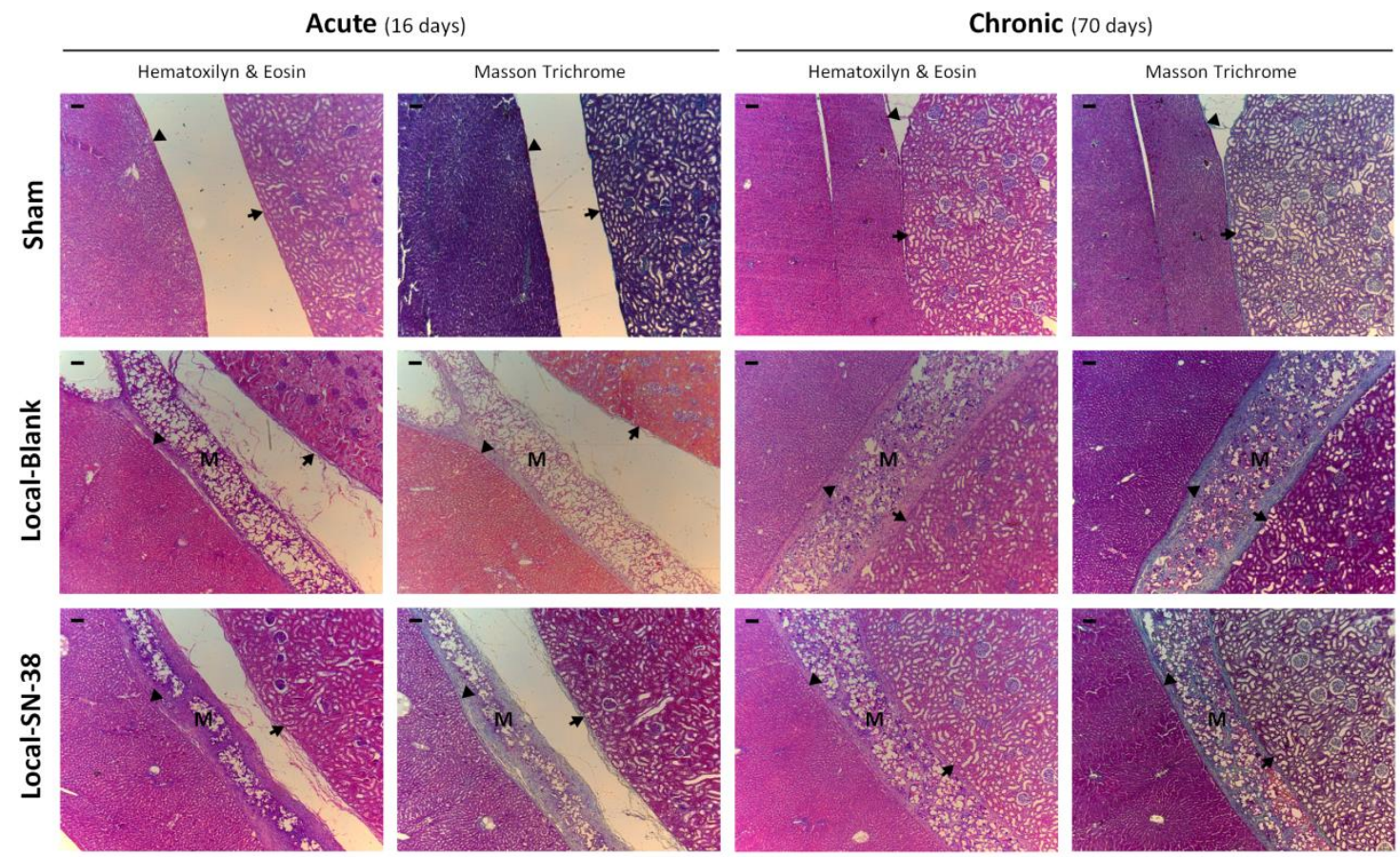

Figure 4. Histology of the Hepatorenal model upon acute (16 day) or chronic (70 days) exposure to local treatments. (M): matrix; arrow heads: liver; arrows: kidney. Representative pictures are shown. Scale bars are $100 \mu \mathrm{m}$. 


\section{WILEY-VCH}
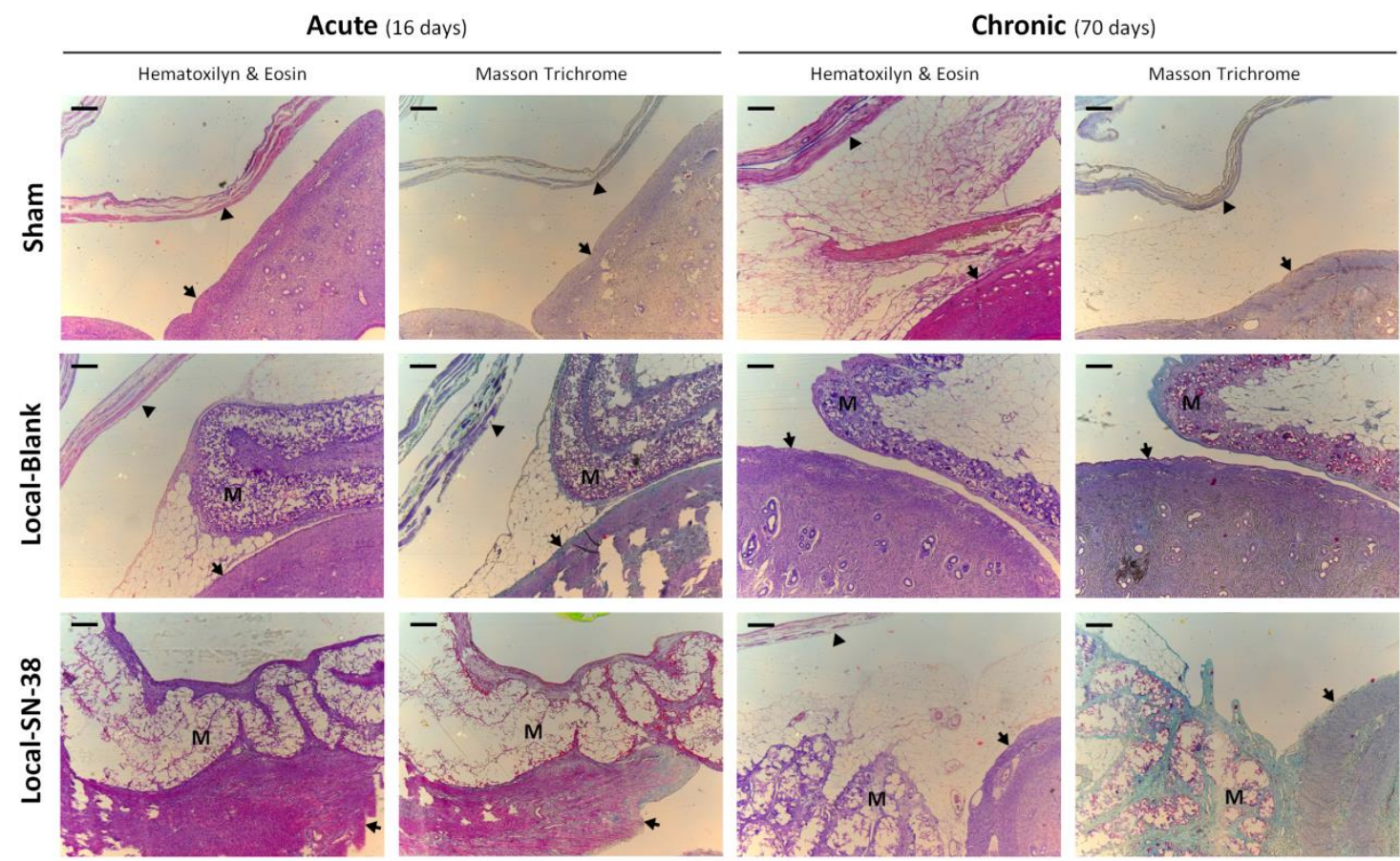

Figure 5. Histology of the Bladder model upon acute (16 day) or chronic (70 days) exposure to local treatments. (M): matrix; arrow heads: bladder wall (not visible in all samples due to farther disposition of the matrices in relation to bladder); arrows: uterus. Representative pictures are shown. Scale bars are $100 \mu \mathrm{m}$.

The mean thickness of the matrices in the FFPE sections was $394 \mu \mathrm{m}$ (range 192 - 958 $\mu \mathrm{m})$. Matrices appeared thicker in the Neurovascular group than in the Hepatorenal and Bladder groups $(\mathrm{P}=0.013$ at 16-day exposure and $\mathrm{P}=0.001$ at the 70 -day exposure samples; ANOVA). This was likely due to the bending of the matrices during the surgical insertion to wrap around the narrow neurovascular bundles instead of an almost flat disposition on the surface of the other two models.

Animals who received LDDSs presented chronic granulomatous inflammation with foreign body response, foreign body giant multinucleated cells and fibrous encapsulation of the matrices, independently of the location of the matrix (Figure 3, 4 and 5). Conversely, in the Sham groups, we observed only chronic inflammatory infiltrate -including scattered multinucleated cells- related to the sutures but no changes in the remaining structures related with the surgical procedure. 


\section{WILEY-VCH}

All FFPE samples from animals receiving LDDSs presented a capsule quality score of 3 (loose fibrous capsule) or 4 (thick and mature capsule). The capsule was less mature in the Hepatorenal and Bladder models as compared to the Neurovascular but differences were not statistically significant. The presence of $\mathrm{SN}-38$ in the matrices did not modify the quality scores as compared to blank matrices. Mean $( \pm \mathrm{SD})$ scores at day 16 were 3.8 \pm 0.4 in Neurovascular, $3.2 \pm 0.4$ in Hepatorenal, and $3.3 \pm 0.5$ in Bladder. Scores did not increase significantly at day 70 . We did not observe infiltration of lymphocytes or neutrophils, nor infection in any of the models.

Mean capsule thickness was $242 \mu \mathrm{m}$ (range 58-542 $\mu \mathrm{m}$ ), and it was similar between SN-38-treated and Blank-treated groups in the Neurovascular and Bladder models (Figure 6A). Nevertheless, in the Hepatorenal model the mean capsule thickness around local-SN-38 matrices was significantly thicker than around local-blank ones in chronic treatment samples. Comparing models, we observed that the mean capsule thickness was higher in the Neurovascular model than in the Hepatorenal and Bladder ones, independently of the treatment assigned (Figure 6A). This could be due to the matrices wrapping around the neurovascular bundle. Also, the dissection of a non-existing space in the subcutaneous tissue to place the matrices might have led to higher inflammation than the placement on a solid organ without dissecting or damaging its surface.

We counted a minimum of 4 and a maximum of 24 layers of fibroblasts surrounding the matrices. There were no differences in the number of fibroblast layers in the capsule among treatment groups in the Neurovascular and Bladder models. In the Hepatorenal model we found a higher number of fibroblast layers in the 16-day exposure samples of the Local-SN-38 group compared to the samples exposed to local-blank (Figure 6B). At the interface, we observed multiple layers of macrophages and leucocytes between the matrix and the capsule with no signs of infection in the samples. 

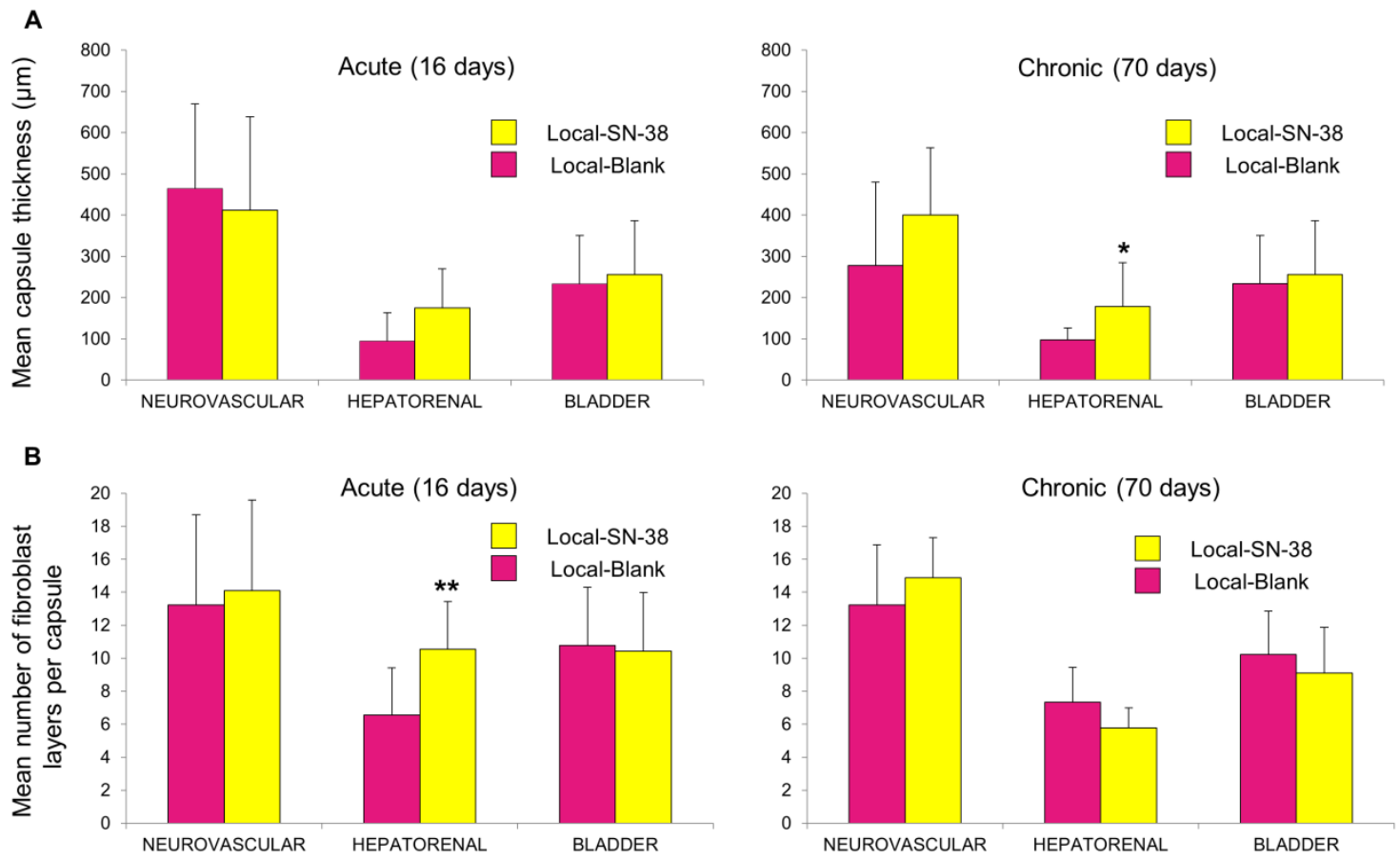

Figure 6. Characterization of the fibrous capsules of the experimental models upon acute (16 days) and chronic (70 days) exposure to LDDS matrices. (A) Capsule thickness in $\mu \mathrm{m}$ (mean and SD of 3 animals). (B) Number of fibroblast layers in the capsules (mean and SD of 3 animals). $* \mathrm{P}=0.0436$ and $* * \mathrm{P}=0.007$, compared to samples exposed to local-blank matrices at the same time point ( $t$ test).

\subsection{Neurovascular function}

None of the animals in which the femoral neurovascular bundle was isolated and wrapped around with the matrices developed ambulation concerns such as limp, weakness or rigidity during all the experimental process. This is consistent with the histologic findings in which the artery, vein and nerve appeared normal after being in contact with the SN-38-eluting LDDS. The rotarod test helped assess this in an objective way. All the animals presented a positive rotarod test the day before the surgery and at the endpoint. Comparing the results at days 0, 3, 16 and the following weeks we observed no differences between treatment groups. Thus, animals conserved the motor function upon the exposure to local-SN-38 and local-blank treatments.

\subsection{Renal and hepatic function}


We evaluated the renal and hepatic function by the analysis of serum creatinine and alanine aminostransferase (ALT) concentrations in the Hepatorenal and Bladder models at days 0, 16 and 70 (Table 1). Creatinine levels were in the 15.0-64.6 $\mu \mathrm{mol} \mathrm{L}^{-1}$ range (median $\left.=33.6 \mu \mathrm{mol} \mathrm{L}^{-1}\right)$. Local-SN-38 matrices did not cause increase in serum creatinine concentrations in any case. We observed a progressive increase in creatinine serum concentrations in all the animals, which was more intense in unilateral nephrectomized rats that surpassed the reference intervals proposed by Boehm et al., ${ }^{[1]}$ probably as a consequence of single kidney resection and animal aging.

Table 1. Blood biochemistry results (mean and SD of 3-6 animals) for renal (Creatinine, Cre) and hepatic (ALT) functions.

\begin{tabular}{|c|c|c|c|c|c|c|c|}
\hline Model & Treatment & $\begin{array}{c}\text { Cre } \\
{\left[\mu \mathrm{mol} \mathrm{L}^{-1}\right]} \\
\text { Day } 0\end{array}$ & $\begin{array}{c}\text { Cre } \\
{\left[\mu \mathrm{mol} \mathrm{L^{-1 } ]}\right.} \\
\text { Day } 16\end{array}$ & $\begin{array}{c}\text { Cre } \\
{\left[\mu \mathrm{mol} \mathrm{L}^{-1}\right]} \\
\text { Day } 70\end{array}$ & $\begin{array}{c}\text { ALT } \\
{\left[\mathbf{I U} \mathbf{L}^{-1}\right]^{\mathbf{a})}} \\
\text { Day 0 }\end{array}$ & $\begin{array}{c}\text { ALT } \\
{\left[\mathbf{I U ~ L ^ { - 1 } ]}\right.} \\
\operatorname{Day} 16\end{array}$ & $\begin{array}{c}\text { ALT } \\
{\left[\mathrm{IU} \mathrm{L}^{-1}\right]} \\
\text { Day } 70\end{array}$ \\
\hline \multirow{3}{*}{ 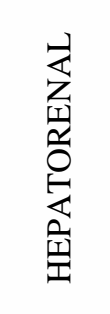 } & Sham & $\begin{array}{c}22.2 \\
( \pm 1.4)\end{array}$ & $\begin{array}{c}43.7 \\
( \pm 10.1)\end{array}$ & $\begin{array}{c}56.6 \\
( \pm 0.8)\end{array}$ & $\begin{array}{c}33.2 \\
( \pm 5.3)\end{array}$ & $\begin{array}{c}43.2 \\
( \pm 5.46)\end{array}$ & $\begin{array}{c}50 \\
( \pm 6.2)\end{array}$ \\
\hline & Local-Blank & $\begin{array}{c}21.7 \\
( \pm 2.3)\end{array}$ & $\begin{array}{c}34.4 \\
( \pm 1.9)\end{array}$ & $\begin{array}{c}59.3 \\
( \pm 4.8)\end{array}$ & $\begin{array}{c}27.8 \\
( \pm 2.9)\end{array}$ & $\begin{array}{c}38.5 \\
( \pm 8.7)\end{array}$ & $\begin{array}{c}35.7 \\
( \pm 4.0)\end{array}$ \\
\hline & Local-SN-38 & $\begin{array}{c}22.7 \\
( \pm 0.7)\end{array}$ & $\begin{array}{c}42.7 \\
( \pm 10.0)\end{array}$ & $\begin{array}{c}59.6 \\
( \pm 2.7)\end{array}$ & $\begin{array}{c}32.7 \\
( \pm 6.8)\end{array}$ & $\begin{array}{c}46.0 \\
( \pm 3.8)\end{array}$ & $\begin{array}{c}36.3 \\
( \pm 3.2)\end{array}$ \\
\hline \multirow{3}{*}{$\frac{\alpha}{\frac{1}{0}}$} & Sham & $\begin{array}{c}29.4 \\
( \pm 5.1)\end{array}$ & $\begin{array}{c}34.8 \\
( \pm 10.2)\end{array}$ & $\begin{array}{c}46.2 \\
( \pm 2.1)\end{array}$ & $\begin{array}{c}61.3 \\
( \pm 45.6)\end{array}$ & $\begin{array}{c}45.0 \\
( \pm 14.1)\end{array}$ & $\begin{array}{c}48.3 \\
( \pm 8.5)\end{array}$ \\
\hline & Local-Blank & $\begin{array}{c}23.3 \\
( \pm 3.1)\end{array}$ & $\begin{array}{c}39.9 \\
( \pm 7.4)\end{array}$ & $\begin{array}{c}51.9 \\
( \pm 0.8)\end{array}$ & $\begin{array}{c}34.3 \\
( \pm 6.9)\end{array}$ & $\begin{array}{c}42.7 \\
( \pm 10.2)\end{array}$ & $\begin{array}{c}43.7 \\
( \pm 1.5)\end{array}$ \\
\hline & Local-SN-38 & $\begin{array}{c}25.1 \\
( \pm 5.1)\end{array}$ & $\begin{array}{l}38.4 \\
( \pm .8)\end{array}$ & $\begin{array}{c}50.0 \\
( \pm 3.5)\end{array}$ & $\begin{array}{c}33.8 \\
( \pm 6.6)\end{array}$ & $\begin{array}{c}43.2 \\
( \pm 13.1)\end{array}$ & $\begin{array}{c}41.3 \\
( \pm 8.1)\end{array}$ \\
\hline
\end{tabular}

${ }^{a}$ International units per liter

ALT and aspartate aminotransferase (AST) are commonly used as screening for liver damage and their serum concentrations rise during hepatocellular injury; ${ }^{[12]}$ ALT is the most specific biomarker of both. ${ }^{[13]}$ ALT concentrations were in the $20-153 \mathrm{IU} \mathrm{L}^{-1}$ range $\left(\right.$ median $\left.=38 \mathrm{IU} \mathrm{L}^{-1}\right)$ and exposure to LDDSs did not alter the values. 


\section{WILEY-VCH}

Levels of total bilirubin, bilirubin fractions and gamma-glutamyl transpeptidase (GGT) serum concentrations were not detectable in most cases due to serum concentrations below the sensitivity of the methods used in clinical practice. Determinations of AST serum concentrations were dramatically interfered by the hemolysis produced during blood collection, so this parameter was not evaluable.

\subsection{Results on skin healing}

Five of eighteen animals of the Neurovascular biocompatibility model presented wound dehiscence the first $24 \mathrm{~h}$ after surgery because rats removed part of the surgical staples. Two of them belonged to the Sham group, two to the Local-Blank group and one to the Local-SN-38 group. No exposure of the nanofiber matrix was observed in any of these animals. Three animals required skin closure under anesthesia (one in each group). No further incidents in the skin healing process were observed during the follow up. The histologic study at endpoint did not reveal any scarring interference in any of the animals (Figure 7). 

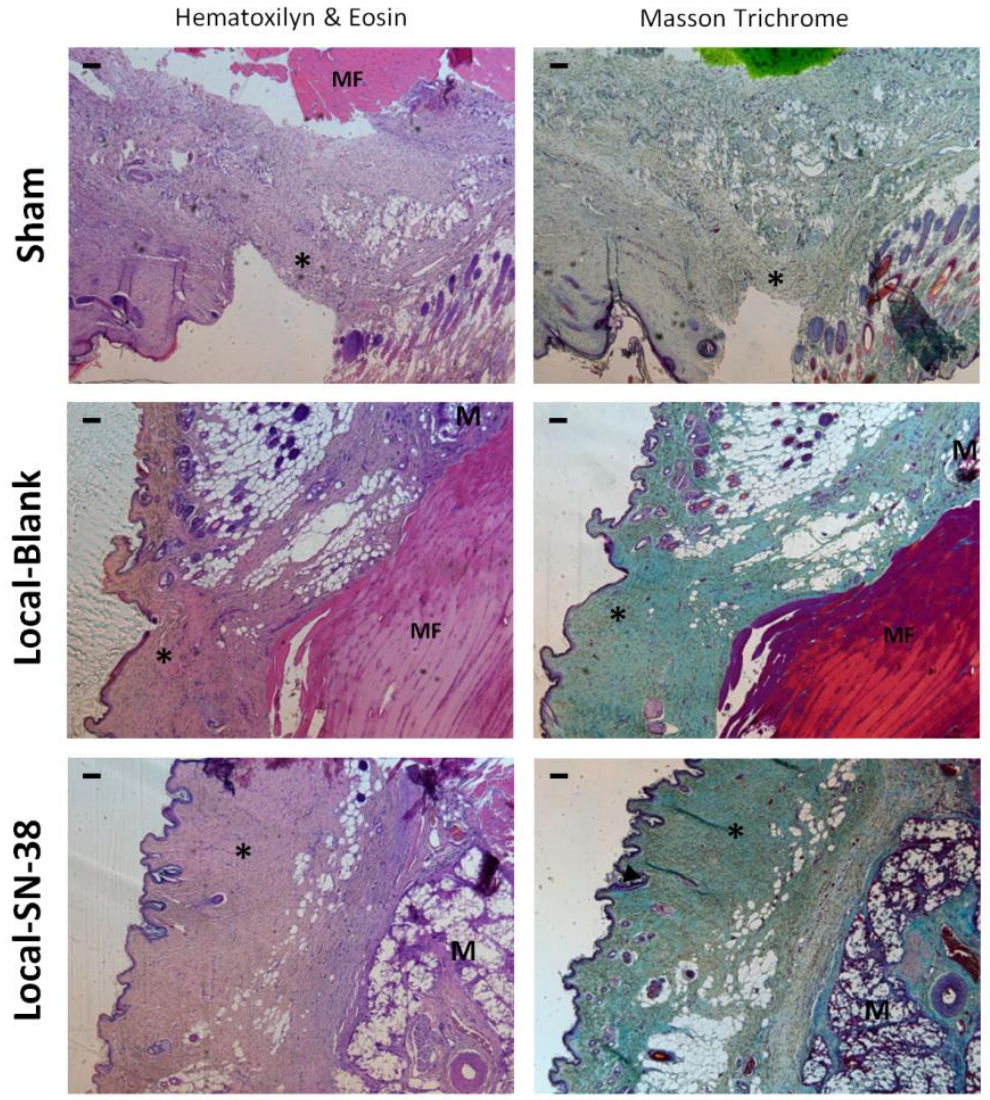

Figure 7. Histology of the skin wound at day 70 after matrix implantation or 16 days after sham surgery. (M): matrix; (MF): muscular fibers; (*): scarring tissue.

Representative pictures are shown. Scale bars are $100 \mu \mathrm{m}$.

\subsection{Blood counts}

Hemoglobin ( $\mathrm{Hb})$, hematocrit (Hct), white blood cell count (WBC) and platelet count

(PC) were assessed in the Hepatorenal and Bladder models at days 0, 16 and 70. Values were in the normal range and we did not find significant differences among treatments (Table 2). 
WILEY-VCH

Table 2. Blood count parameters (mean \pm SD of 3-6 values).

\begin{tabular}{|c|c|c|c|c|c|c|c|c|c|c|c|c|c|}
\hline Model & Treatment & $\begin{array}{l}\text { Hb } \\
{\left[g_{d L}{ }^{-1}\right]} \\
\text { Day } 0\end{array}$ & $\begin{array}{l}\text { Hb } \\
{\left[\mathrm{g} \mathrm{dL}^{-1}\right]} \\
\operatorname{Day} 16\end{array}$ & $\begin{array}{l}\text { Hb } \\
{\left[\mathrm{g} \mathrm{dL}^{-1}\right]} \\
\text { Day } 70\end{array}$ & $\begin{array}{l}\text { Het } \\
{[\%]} \\
\text { Day } 0\end{array}$ & $\begin{array}{l}\text { Hct } \\
{[\%]} \\
\text { Day } 16\end{array}$ & $\begin{array}{l}\text { Hct } \\
{[\%]} \\
\text { Day } 70\end{array}$ & $\begin{array}{l}\text { WBC } \\
{\left[10^{3} \mu L^{-1}\right]} \\
\text { Day } 0\end{array}$ & $\begin{array}{l}\text { WBC } \\
{\left[10^{3} \mu L^{-1}\right]} \\
\text { Day } 16\end{array}$ & $\begin{array}{l}\text { WBC } \\
{\left[10^{3} \mu L^{-1}\right]} \\
\text { Day } 70\end{array}$ & $\begin{array}{l}\text { PC } \\
{\left[10^{5} \mu L^{-1}\right]} \\
\text { Day } 0\end{array}$ & $\begin{array}{l}\text { PC } \\
{\left[10^{5} \mu L^{-1}\right]} \\
\text { Day } 16\end{array}$ & $\begin{array}{l}\text { PC } \\
{\left[10^{5} \mu L^{-1}\right]} \\
\text { Day } 70\end{array}$ \\
\hline \multirow{3}{*}{ 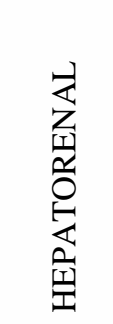 } & Sham & $\begin{array}{l}13.0 \\
( \pm 0,5)\end{array}$ & $\begin{array}{l}14.1 \\
( \pm 0.6)\end{array}$ & $\begin{array}{l}15.6 \\
( \pm 0.3)\end{array}$ & $\begin{array}{l}36.2 \\
( \pm 2.1)\end{array}$ & $\begin{array}{l}42.4 \\
( \pm 4.2)\end{array}$ & $\begin{array}{l}49.9 \\
( \pm 2.0)\end{array}$ & $\begin{array}{l}8.8 \\
( \pm 2.6)\end{array}$ & $\begin{array}{l}8.9 \\
( \pm 2.2)\end{array}$ & $\begin{array}{l}7.4 \\
( \pm .4)\end{array}$ & $\begin{array}{l}5.8 \\
( \pm 7.6)\end{array}$ & $\begin{array}{l}9.0 \\
( \pm 1.5)\end{array}$ & $\begin{array}{l}8.4 \\
( \pm 0.1)\end{array}$ \\
\hline & $\begin{array}{l}\text { Local- } \\
\text { Blank }\end{array}$ & $\begin{array}{l}12.4 \\
( \pm 0.9)\end{array}$ & $\begin{array}{l}13.7 \\
( \pm 0.9)\end{array}$ & $\begin{array}{l}16.0 \\
( \pm 0.3)\end{array}$ & $\begin{array}{l}33.5 \\
( \pm 3.4)\end{array}$ & $\begin{array}{l}40.6 \\
( \pm 5.6)\end{array}$ & $\begin{array}{l}50.3 \\
( \pm 1.2)\end{array}$ & $\begin{array}{l}7.9 \\
( \pm 2.1)\end{array}$ & $\begin{array}{l}8.8 \\
( \pm 2.8)\end{array}$ & $\begin{array}{l}6.0 \\
( \pm 2.4)\end{array}$ & $\begin{array}{l}5.9 \\
( \pm 0.8)\end{array}$ & $\begin{array}{l}8.6 \\
( \pm 1.5)\end{array}$ & $\begin{array}{l}8.6 \\
( \pm 1.8)\end{array}$ \\
\hline & $\begin{array}{l}\text { Local- } \\
\text { SN-38 }\end{array}$ & $\begin{array}{l}13.0 \\
( \pm 0.4)\end{array}$ & $\begin{array}{l}14.3 \\
( \pm 1.1)\end{array}$ & $\begin{array}{l}15.5 \\
( \pm 0.4)\end{array}$ & $\begin{array}{l}35.9 \\
( \pm 1.4)\end{array}$ & $\begin{array}{l}41.8 \\
( \pm 5.2)\end{array}$ & $\begin{array}{l}48.5 \\
( \pm 0.8)\end{array}$ & $\begin{array}{l}9.1 \\
( \pm .8)\end{array}$ & $\begin{array}{l}8.4 \\
( \pm 4.1)\end{array}$ & $\begin{array}{l}4.4 \\
( \pm 0.3)\end{array}$ & $\begin{array}{l}6.4 \\
( \pm 1.7)\end{array}$ & $\begin{array}{l}8.7 \\
( \pm 0.6)\end{array}$ & $\begin{array}{l}8.1 \\
( \pm 0.4)\end{array}$ \\
\hline \multirow{3}{*}{ 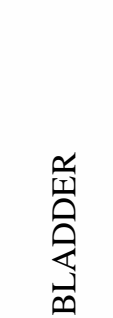 } & Sham & $\begin{array}{l}14.2 \\
( \pm 1.1)\end{array}$ & $\begin{array}{l}13.9 \\
( \pm 0.6)\end{array}$ & $\begin{array}{l}15.1 \\
( \pm 0.7)\end{array}$ & $\begin{array}{l}42.5 \\
( \pm 5.8)\end{array}$ & $\begin{array}{l}39.9 \\
( \pm 3.3)\end{array}$ & $\begin{array}{l}46.7 \\
( \pm 3.8)\end{array}$ & $\begin{array}{l}8.5 \\
( \pm 2.3)\end{array}$ & $\begin{array}{l}6.5 \\
( \pm 2.8)\end{array}$ & $\begin{array}{l}3.3 \\
(2.3)\end{array}$ & $\begin{array}{l}9.0 \\
( \pm .2)\end{array}$ & $\begin{array}{l}9.0 \\
( \pm 1.2)\end{array}$ & $\begin{array}{l}8.5 \\
( \pm 1.3)\end{array}$ \\
\hline & $\begin{array}{l}\text { Local- } \\
\text { Blank }\end{array}$ & $\begin{array}{l}12.9 \\
( \pm 0.7)\end{array}$ & $\begin{array}{l}14.5 \\
( \pm 1.0)\end{array}$ & $\begin{array}{l}14.6 \\
( \pm 0.2)\end{array}$ & $\begin{array}{l}35.6 \\
( \pm 3.0)\end{array}$ & $\begin{array}{l}43.5 \\
( \pm 5.0)\end{array}$ & $\begin{array}{l}44.2 \\
( \pm 0.3)\end{array}$ & $\begin{array}{l}7.1 \\
( \pm 2.3)\end{array}$ & $\begin{array}{l}7.8 \\
( \pm 2.4)\end{array}$ & $\begin{array}{l}5.4 \\
( \pm 3.0)\end{array}$ & $\begin{array}{l}6.1 \\
( \pm 1.5)\end{array}$ & $\begin{array}{l}7.6 \\
( \pm 1.1)\end{array}$ & $\begin{array}{l}8.4 \\
( \pm 0.2)\end{array}$ \\
\hline & $\begin{array}{l}\text { Local- } \\
\text { SN-38 }\end{array}$ & $\begin{array}{l}12.6 \\
( \pm 1.0)\end{array}$ & $\begin{array}{l}14.3 \\
( \pm 0.6)\end{array}$ & $\begin{array}{l}15.4 \\
( \pm 0.6)\end{array}$ & $\begin{array}{l}35.7 \\
( \pm 3.5)\end{array}$ & $\begin{array}{l}42.1 \\
( \pm 3.5)\end{array}$ & $\begin{array}{l}46.2 \\
( \pm 1.3)\end{array}$ & $\begin{array}{l}8.1 \\
( \pm 1.3)\end{array}$ & $\begin{array}{l}8.2 \\
( \pm 2.0)\end{array}$ & $\begin{array}{l}7.0 \\
( \pm 1.4)\end{array}$ & $\begin{array}{l}6.2 \\
( \pm 0.7)\end{array}$ & $\begin{array}{l}7.2 \\
( \pm 2.0)\end{array}$ & $\begin{array}{l}8.1 \\
( \pm 0.8)\end{array}$ \\
\hline
\end{tabular}




\section{WILEY-VCH}

\subsection{Weight and other clinical signs of systemic toxicity}

During the study the animals did not show signs of wellbeing loss, diarrhea, anorexia or other clinical signs. All animals gained weight at the end of the follow up regardless of the assigned group, and none of them presented weight loss greater than $10 \%$ at any time point (Supplemental Figure 1).

\section{Discussion}

After gross tumor resection, vital tissue structures such as vessels, nerves and solid viscera may contain macro- or microscopic tumor rests. ${ }^{[1 a, 14]}$ Peritumoral tissues remain exposed and sometimes partially damaged by the severity of the surgery, so it is important to determine whether the placement of any suitable anticancer LDDS in the surgical bed could lead to tissue-specific local toxicity. Our study provides the first comprehensive exploration of the compatibility of SN-38-loaded polymer nanofiber matrices in a model of healthy cells (murine hepatocytes) and in several tissues of the Wistar rat as a model of healthy tissues and organs. At the dosage studied ( $18 \mu \mathrm{g} \mathrm{SN}-38 / \mathrm{cm}^{2}$, for a total of $36 \mu \mathrm{g} \mathrm{SN}-38$, corresponding to $0.17 \mathrm{mg} \mathrm{kg}^{-1}$ for a mean rat weight of $215 \mathrm{~g}$ at treatment start), this LDDS was safe for the adjacent non-tumor tissue as demonstrated by several histology and functional analyses, and did not interfere with skin healing.

We expected that FDA-approved PLA and PLGA polymers would cause foreign body reactions in the surrounding tissue, as previously described, ${ }^{[15]}$ but we are the first to address the functional effect of such local reactions upon wrapping around a neurovascular bundle with SN-38-loaded PLA/PLGA nanofiber matrices. In the femoral neurovascular bundle, the femoral nerve innervates the quadriceps muscle -the major extensor muscle of the knee- ${ }^{[16]}$ and the occlusion of the femoral artery can cause walking disturbance in rats during the first 2 to 5 days after an injury. ${ }^{[17]}$ Our functional study showed that malleable nanofiber matrices are suitable to embrace vital neurovascular structures without causing a functional damage even 


\section{WILEY-VCH}

upon eluting SN-38 at high localized concentrations. Similarly, our results demonstrate that vital organs such as liver, kidney, urinary bladder and other structures in abdominal or pelvic locations are not damaged by this delivery system. This biocompatibility property opens new clinical possibilities for the application of the LDDS in the chemotherapy of surgically resected solid tumors. For example, in the field of pediatric oncology, $8 \%$ of neuroblastomas are not suitable for gross total resection due to the involvement of vascular and nerve structures and $55 \%$ of surgery-eligible patients still have disease after resection. ${ }^{[18]}$ In addition, one out of ten patients will suffer vascular injury of a major vessel during surgery, which leads to nephrectomy in 5-10\% of them. ${ }^{[19]}$ The embryonal subtype of rhabdomyosarcoma, a common soft tissue sarcoma in childhood, frequently appears in the genitourinary location in less than 10 year old patients. ${ }^{[20]}$ In this pelvic location, complete resection surgery is challenging and novel LDDS might help avoid undesirable damage or loss of pelvic organs that jeopardize the quality of life of young patients. ${ }^{[21]}$ Similarly, other frequent non-central nervous system pediatric solid tumors such as Ewing sarcomas and synovial sarcomas usually appear in the proximity of vessels and nerves as their most frequent locations are pelvis, axial skeleton and extremities; $17 \%$ of patients with Ewing sarcoma will present local or combined (local and systemic) relapse after primary treatment. ${ }^{[2]}$ These patients would also be adequate candidates to receive the LDDS upon a subtotal resection surgery involving such vital structures. In pediatric cancer it is critical to ensure that off-target toxicity is reversible because these patients are likely to be long-term survivors. It is estimated that upon receiving currently available treatments, two thirds of pediatric cancer survivors will present at least one undesirable late-effect related to the cancer therapy, and one third will have serious lifethreatening complications. ${ }^{[23]}$

Because in a previous study we observed that the drug elutes from the nanofibers following a bimodal release rate in vivo and penetrates $2 \mathrm{~mm}$ in the surrounding solid tumor tissue, ${ }^{[6]]}$ we expected that the matrices eluting $\mathrm{SN}-38$ would produce higher inflammation than blank 


\section{WILEY-VCH}

matrices in the adjacent organs. Among the models studied, only in the Hepatorenal we observed that SN-38-loaded systems produced more local inflammation (measured as the thickness of the fibrous capsule) than the blank counterparts. This could be explained by the susceptibility of the liver to irinotecan toxicity, ${ }^{[24]}$ and by our in vitro experiments in murine hepatocytes, although we did not find hepatocellular damage or liver function alterations in the rats exposed to local-SN-38. Our findings in blood counts, liver and kidney function were consistent with the absence of histologic damage of the tissues in contact with the matrices. Our study finished 70 days after the insertion of the matrices and thus we did not address the biodegradability of the LDDS. However, it is likely that the matrices would be eliminated in the long term in the organism because they are made of hydrolytically degradable polyesters $^{[25]}$. PLA is a slow degradation polymer (> 1 year) while PLGA $(75 / 25)$ is degraded in 4-5 months by hydrolysis ${ }^{[25]}$. Additionally, the observed foreign body reaction suggests that the system would be eliminated actively due to the release of degradation mediators such as reactive oxygen intermediates, lytic enzymes and acid from the macrophages and foreign body giant cells ${ }^{[15 b]}$.

Systemic adverse events upon the administration of irinotecan include diarrhea and myelosuppression. ${ }^{[2]}$ Plasma exposure to irinotecan-derived SN-38 is considered the main responsible of diarrhea due to intestinal mucosal damage after its biliary excretion. ${ }^{[27]}$ Acute systemic adverse effects are rarely observed in rats receiving single intravenous administrations of up to $68 \mathrm{mg} \mathrm{kg}^{-1}$ of irinotecan -which would expose the organism to very high plasma concentrations of SN-38-, ${ }^{[28]}$ while in our current study local SN-38 dosages were around 400-fold lower, which would lead to very low SN-38 exposure in plasma upon drug absorption from the administration site. For instance, in a previous study we found very low and transient plasma SN-38 concentrations $\left(1 \mathrm{ng} \mathrm{mL}^{-1}\right)$ in mice after a single local administration of $1 \mathrm{~cm}^{2}$ of LDDS loaded with $18 \mu \mathrm{g} \mathrm{SN}-38$-equivalent to $0.7 \mathrm{mg} \mathrm{kg}^{-1}$ for mice weighing $25 \mathrm{~g}-.{ }^{[6]}$ Overall, our results confirm that the low systemic exposure after 


\section{WILEY-VCH}

local-SN-38 administration does not interfere with bone marrow function. Nevertheless, since granulocyte colony stimulating factor is used in the clinic to prevent neutropenia, myelosupression is no longer a limiting factor for current regimens of camptothecins in the clinical practice. ${ }^{[29]}$

\section{Conclusion}

Our study demonstrates the feasibility to apply anticancer SN-38 loaded nanofiber matrices next to vital organs and tissues without any significant detrimental effect on the surrounding tissues, blood and vital organs, and paves the way for translating this modular delivery technology to the clinic.

\section{Experimental section}

Preparation and characterization of polymer nanofiber matrices loaded with SN-38 microcrystals

SN-38-loaded nanofiber matrices (local-SN-38) were produced by electrospinning a 1:1 mixture of PLA (MW > $100 \mathrm{~kg} \mathrm{~mol}^{-1}$, Velox GmbH, Hamburg, Germany) and PLGA (MW $95 \mathrm{~kg} \mathrm{~mol}^{-1}$; lactic:glycolic ratio 75:25, Corbion, Amsterdam, Netherlands) and simultaneous electrospraying of SN-38 microcrystals. ${ }^{[6 e]}$ Matrices without SN-38 (local-blank) were also manufactured though without the cospraying of the microcrystals. The matrices were kept at $20^{\circ} \mathrm{C}$ until they were used.

The release profile of $\mathrm{SN}-38$ from the matrices was characterized in vitro in medium containing the solubilizer HPBCD (molecular weight of $1400 \mathrm{~g} \mathrm{~mol}^{-1}$; Sigma Aldrich, St. Louis, MO). SN-38 was quantified by HPLC, as previously described. ${ }^{[6 e]}$ Cell lines and cytotoxicity assays 


\section{WILEY-VCH}

Mouse hepatocytes (H2.35; ATCC, Manassas, VA) were cultured in DMEM high glucose

medium supplemented with $10 \%$ fetal bovine serum, 50 units $\mathrm{mL}^{-1}$ penicillin and $50 \mathrm{mg} \mathrm{mL}^{-1}$ streptomycin (Life Technologies, Grand Island, NY) at $37^{\circ} \mathrm{C}$ and $5 \% \mathrm{CO}_{2}$.

Cell lines of pediatric solid tumors (Ewing sarcoma SK-ES-1 and rhabdomyosarcoma Rh30) were obtained from the repository maintained at Hospital Sant Joan de Deu (Barcelona, Spain) and cultured as previously described. ${ }^{[6]]}$

The antiproliferative activity of SN-38 was characterized with the MTS assay (Promega, Fitchburg, WI) and IC50 $\pm 95 \%$ confidence intervals were calculated as previously described. ${ }^{[6 e]}$ The cytotoxicity of SN-38 was assessed using the LDH cytotoxicity assay kit from Pierce (Rockford, IL). For the LDH assay, 3,000 cells (mouse hepatocytes or human Ewing sarcoma and rhabdomyosarcoma) were plated per well in 96-well plates and cultured until monolayers covered the surface of the well. Then, SN-38 was added to the plate at concentrations ranging 1-0.00000256 nM). At $72 \mathrm{~h} \mathrm{LDH}$ release from the cells was assessed. The antiproliferative activity of SN-38-loaded matrices was evaluated with the MTS assay as previously described. ${ }^{[6]}$ Blank matrices (no SN-38 content) were used as controls.

\section{Animals and surgical implantation of matrices}

Fifty-four 9 week-old female Wistar rats were used (Janvier, Zentralinstitut für Versuchstierzucht, Hannover, Germany). Animals were housed under standard conditions with water and chow ad libitum. The protocol was approved by the Animal Ethics Committee of the Universidad de Barcelona (approval number 8625) in accordance with the local, national and European legislation. All the animals were supervised and weighed the day of the surgery and weekly thereafter and clinical signs including wellbeing loss, limp, weakness or rigidity of hind limb, diarrhea and anorexia were recorded.

Treatments ( $2 \times 1 \mathrm{~cm}$ matrices) were fastened to the target locations using one 4/0 PLGA suture. Special attention was paid on the wound during postoperative supervision. The suture clips were removed one week after the surgery. All the surgeries were performed under 


\section{WILEY-VCH}

general anesthesia with isoflurane and analgesia with subcutaneous buprenorphine was administrated during the first $48 \mathrm{~h}$ after surgery. The muscular layer was sutured when needed with 4/0 PLGA sutures (Novosyn, B. Braun Medical AS, Spain) and the skin was closed using suture clips (Michel Suture Clips 11 x 2 mm, FST, Germany).

At the experimental endpoint blood samples were obtained under ketamine/xylacine general anesthesia through cardiac puncture. After that, we performed left ventricle catheterization and wide right atrium opening. The animals were then perfused with $60 \mathrm{~mL}$ of PBS followed by $60 \mathrm{~mL}$ of $4 \%$ formaline. The following tissues were collected for histologic evaluation: skin covering the treatment area, neurovascular bundle and portion of muscle in contact (Neurovascular model), right kidney and portion of liver in contact with the right kidney (Hepatorenal model) and bladder, a portion of uterus and rectum (Bladder model).

\section{Functional assessment of neurovascular harm}

To assess the function of the hind limb in the experimental Neurovascular model, the rotarod performance test (Accelerating Rota Rod for 4 Rats, Panlab, Barcelona, Spain) was performed the day before the surgery and at days 3,16 and weekly until the animals were sacrificed. A positive performance test was considered if the animal remained on the rotating rod during 5 min in 2 of maximum 3 opportunities at 10 rpm constant speed. All the animals were trained in the test 2 weeks before the surgery.

\section{Histology}

Samples were fixed in $4 \%$ formalin, dehydrated in sequential concentrations of ethanol and embedded in paraffin. Then, $2 \mu \mathrm{m}$ sections were cut from the FFPE blocks with a rotary microtome (HM 340E, Thermo Scientific, USA) in coronal direction for Hepatorenal, in transversal direction for Neurovascular, and in sagittal direction for Bladder samples. Sections were stained with hematoxylin/eosin. Masson trichrome was used to stain collagen fibers. Samples were examined under light microscope by a blinded expert pathologist who assigned scores in 3 different fields following a histomorphometric scale ${ }^{[30]}$, grading from 0 to 4 the 


\section{WILEY-VCH}

aspect of the capsule -4 corresponds to a thick and mature capsule, 3 to a loose fibrous capsule, 2 to a capsule with dense and granulation tissue containing inflammatory cells and fibroblasts, 1 to inflammatory tissue without signs of fibrous tissue-. The thickness of the capsule and matrices was measured in micrometers in 3 different fields in each sample. We also measured the capsule thickness by counting the number of fibroblast layers in 3 different areas. All the surrounding tissues were inspected looking for signs of histological damage.

\section{Blood sampling}

Blood tests were performed in the experimental Hepatorenal and Bladder models the day of the surgery and at day 16 and 70 . By retro-orbital sinus puncture, $500 \mu \mathrm{L}$ of blood was collected in a $1.5 \mathrm{~mL}$ Eppendorf tube with $100 \mu \mathrm{L}$ of EDTA 0,5 M (Sigma-Aldrich, Tres Cantos, Spain) and three $75 \mu \mathrm{L}$ heparinized hematocrit capillaries (Deltalab, Barcelona, Spain) were filled. The day of sacrifice blood collection was performed by cardiac puncture and placed in K2EDTA and Z Serum Sep Clot Activator tubes (Vacuette, Greiner bio-one, Kremsmünster, Austria).

We evaluated blood counts including $\mathrm{Hct}, \mathrm{WBC}, \mathrm{PC}$ and $\mathrm{Hb}$ with a hematology analyzer (ADVIA 2120, Siemens Healthcare, Erlangen, Germany). Creatinine, ALT, GGT, AST and bilirubin serum concentrations were analyzed by molecular absorption spectrometry (ARCHITECT c8000, Abott, IL, USA).

\section{Statistics}

Statistical analyses were carried out using GraphPad Prism 5 software (La Jolla, CA). Histologic images were obtained from three different microscopic fields from each sample of each animal allocated in each subgroup. Capsule scores, capsule thickness, number of fibroblasts in the capsule, matrix thickness, serum biochemistry, blood counts and weight were presented as means $\pm \mathrm{SD}$. We applied the Student's $t$ test to compare data from two treatment conditions or two sampling times and the ANOVA test to compare data from the three models. To compare the performance of rats in the rotarod test (3-10 animals per group), 


\section{WILEY-VCH}

we performed Pearson's Chi-square test. We considered the differences statistically

significant if $\mathrm{p}$ value was $<0.05$.

\section{Supporting Information}

Supporting Information is available from the Wiley Online Library or from the author.

\section{Acknowledgements}

C.A.R.-P., G.B. and H.C.-E. contributed equally to this work. A.M.C. acknowledges funding from ISCIII-FEDER (CP13/00189) and European Union Seventh Framework Programme (FP7/2007-2013) under Marie Curie International Reintegration Grant (PIRG-08-GA-2010276998). This work was partially funded by Cebiotex, a biotechnology company developing nanofiber DDS formulations. C.A.R.-P was funded by the Fred-Hollows Foundation (Sydney, Australia) through the ICO fellowship board (Homburg/Saar, Germany). We thank Eva Rodriguez for technical assistance.

\section{Disclosure}

J.A.T. discloses financial interest (stock options) and is a member of the Board of Directors of Cebiotex. J.A.T. and A.M.C. are inventors in one patent related to the DDS described in the manuscript. The other authors declare no potential conflict of interest.

Received: ((will be filled in by the editorial staff))

Revised: ((will be filled in by the editorial staff)) Published online: ((will be filled in by the editorial staff))

\section{References}

[1] a) M. P. La Quaglia, B. H. Kushner, W. Su, G. Heller, K. Kramer, S. Abramson, N. Rosen, S. Wolden, N.-K. V. Cheung, Journal of Pediatric Surgery 2004, 39, 412; b) M. D. Wharam, J. Meza, J. Anderson, J. C. Breneman, S. S. Donaldson, T. J. Fitzgerald, J. Michalski, L. A. Teot, E. S. Wiener, W. H. Meyer, J Clin Oncol 2004, 22, 1902; c) M. J. Krasin, A. M. Davidoff, C. Rodriguez-Galindo, C. A. Billups, C. E. Fuller, M. D. Neel, T. E. Merchant, Cancer 2005, 104, 367.

[2] N. M. Marina, Q. Liu, S. S. Donaldson, C. A. Sklar, G. T. Armstrong, K. C. Oeffinger, W. M. Leisenring, J. P. Ginsberg, T. O. Henderson, J. P. Neglia, M. A. Stovall, Y. Yasui, R. L. Randall, D. S. Geller, L. L. Robison, K. K. Ness, Cancer 2017, 123, 2551.

[3] K. C. Oeffinger, M. M. Hudson, CA Cancer J Clin 2004, 54, 208.

[4] M. C. Stauder, N. N. Laack, C. R. Moir, P. J. Schomberg, J Pediatr Hematol Oncol 2011, 33, 350 .

[5] M. Cambeiro, F. A. Calvo, J. J. Aristu, M. M. Jimenez, M. San-Julian, J. Alcalde, J. L. Hernandez-Lizoain, M. Jurado, R. Martinez-Monge, Radiother Oncol 2015, 116, 316.

[6] a) E. J. Falde, J. D. Freedman, V. L. Herrera, S. T. Yohe, Y. L. Colson, M. W. Grinstaff, J Control Release 2015, 214, 23; b) R. Liu, J. B. Wolinsky, P. J. Catalano, L. R. Chirieac, A. J. Wagner, M. W. Grinstaff, Y. L. Colson, C. P. Raut, Ann Surg Oncol 2012, 19, 199; c) J. B. Wolinsky, Y. L. Colson, M. W. Grinstaff, J Control Release 2012, 159, 14; d) J. B. Wolinsky, R. Liu, J. Walpole, L. R. Chirieac, Y. L. Colson, M. W. Grinstaff, J Control Release 2010, 144, 280; e) C. Monterrubio, G. Pascual-Pasto, F. Cano, M. Vila-Ubach, A. Manzanares, P. Schaiquevich, J. A. Tornero, A. Sosnik, J. Mora, A. M. Carcaboso, Biomaterials 2016, 79, 69; f) A. M. Carcaboso, D. A. 


\section{WILEY-VCH}

Chiappetta, J. A. Opezzo, C. Hocht, A. C. Fandino, J. O. Croxatto, M. C. Rubio, A. Sosnik, D. H. Abramson, G. F. Bramuglia, G. L. Chantada, Invest Ophthalmol Vis Sci 2010, 51, 2126.

[7] N. Kaneda, H. Nagata, T. Furuta, T. Yokokura, Cancer Res 1990, 50, 1715.

[8] V. Bala, S. Rao, B. J. Boyd, C. A. Prestidge, J Control Release 2013, 172, 48.

[9] a) S. Palakurthi, Expert Opin Drug Deliv 2015, 12, 1911; b) C. Monterrubio, S. Paco, N. G. Olaciregui, G. Pascual-Pasto, M. Vila-Ubach, M. Cuadrado-Vilanova, M. M. Ferrandiz, H. Castillo-Ecija, R. Glisoni, N. Kuplennik, A. Jungbluth, C. de Torres, C. Lavarino, N. V. Cheung, J. Mora, A. Sosnik, A. M. Carcaboso, J Control Release 2017, 255, 108; c) M. Ramesh, P. Ahlawat, N. R. Srinivas, Biomed Chromatogr 2010, 24, 104; d) S. Tran, P.-J. DeGiovanni, B. Piel, P. Rai, Clinical and Translational Medicine 2017, 6, 44; e) P. Botella, E. Rivero-Buceta, J Control Release 2017, 247, 28.

[10] B. Chiu, J. Coburn, M. Pilichowska, C. Holcroft, F. P. Seib, A. Charest, D. L. Kaplan, Br J Cancer 2014, 111, 708.

[11] O. Boehm, B. Zur, A. Koch, N. Tran, R. Freyenhagen, M. Hartmann, K. Zacharowski, Biol Chem 2007, 388, 547.

[12] E. G. Giannini, R. Testa, V. Savarino, CMAJ 2005, 172, 367.

[13] G. Tarantino, World Journal of Gastroenterology : WJG 2007, 13, 4917.

[14] W. W. Huh, N. C. Daw, C. E. Herzog, M. F. Munsell, M. F. McAleer, V. O. Lewis, Pediatr Blood Cancer 2017, 64.

[15] a) R. C. Mundargi, V. R. Babu, V. Rangaswamy, P. Patel, T. M. Aminabhavi, J Control Release 2008, 125, 193; b) J. M. Anderson, A. Rodriguez, D. T. Chang, Seminars in immunology 2008, 20, 86.

[16] G. B. Gillis, A. A. Biewener, J Exp Biol 2001, 204, 2717.

[17] M. Miyamoto, T. Tayama, S. Yamaguchi, M. Kaneko, H. Kurumatani, Eur J Pharmacol 2006, 545, 173.

[18] S. Avanzini, L. Pio, G. Erminio, C. Granata, K. Holmes, M. Gambart, P. Buffa, V. Castel, D. Valteau Couanet, A. Garaventa, A. Pistorio, G. Cecchetto, G. Martucciello, G. Mattioli, S. Sarnacki, Pediatr Blood Cancer 2017, 64.

[19] A. M. Davidoff, I. Fernandez-Pineda, Semin Pediatr Surg 2016, 25, 395.

[20] R. Dasgupta, J. Fuchs, D. Rodeberg, Seminars in Pediatric Surgery 2016, 25, 276.

[21] K. Kieran, M. Shnorhavorian, Urologic Oncology: Seminars and Original Investigations 2016, 34, 93.

[22] M. Stahl, A. Ranft, M. Paulussen, T. Bolling, V. Vieth, S. Bielack, I. Gortitz, G. Braun-Munzinger, J. Hardes, H. Jurgens, U. Dirksen, Pediatr Blood Cancer 2011, 57, 549.

[23] N. M. Aziz, K. C. Oeffinger, S. Brooks, A. J. Turoff, Cancer 2006, 107, 841.

[24] E. Marcolino Assis-Junior, A. T. Melo, V. B. M. Pereira, D. V. T. Wong, N. R. P. Sousa, C. M. G. Oliveira, L. R. C. Malveira, L. S. Moreira, M. Souza, P. R. C. Almeida, R. C. P. Lima-Junior, Toxicol Appl Pharmacol 2017, 327, 71.

[25] D. Hofmann, M. Entrialgo-Castano, K. Kratz, A. Lendlein, Advanced materials 2009, $21,3237$.

[26] S. Negoro, M. Fukuoka, N. Masuda, M. Takada, Y. Kusunoki, K. Matsui, N. Takifuji, S. Kudoh, H. Niitani, T. Taguchi, J Natl Cancer Inst 1991, 83, 1164.

[27] A. Kurita, S. Kado, N. Kaneda, M. Onoue, S. Hashimoto, T. Yokokura, Cancer Chemother Pharmacol 2000, 46, 211.

[28] F. Lavelle, M. C. Bissery, S. Andre, F. Roquet, J. F. Riou, Semin Oncol 1996, 23, 11.

[29] a) K. Mori, S. Machida, T. Yoshida, M. Yoshida, Y. Kano, K. Tominaga, Cancer Chemother Pharmacol 1999, 43, 467; b) Y. Egusa, Y. Fujiwara, E. Syaharuddin, H. Sumiyoshi, T. Isobe, M. Yamakido, Anticancer Res 1998, 18, 481. 


\section{WILEY-VCH}

[30] D. P. Link, J. van den Dolder, J. J. van den Beucken, V. M. Cuijpers, J. G. Wolke, A. G. Mikos, J. A. Jansen, J Biomed Mater Res A 2008, 87, 760.

Copyright WILEY-VCH Verlag GmbH \& Co. KGaA, 69469 Weinheim, Germany, 2016. 


\section{WILEY-VCH}

ToC entry

Tissue-specific toxicity of SN38-loaded nanofiber matrices -a new delivery system for localized treatment of cancer- was studied in a rat model resembling the clinical condition of pediatric cancer patients undergoing subtotal resection surgery. The product was safe and biocompatible in vital structures including blood vessels, nerves and viscera, opening new clinical opportunities for this patient population.

ToC figure $(50 \mathrm{~mm} \mathrm{~h})$
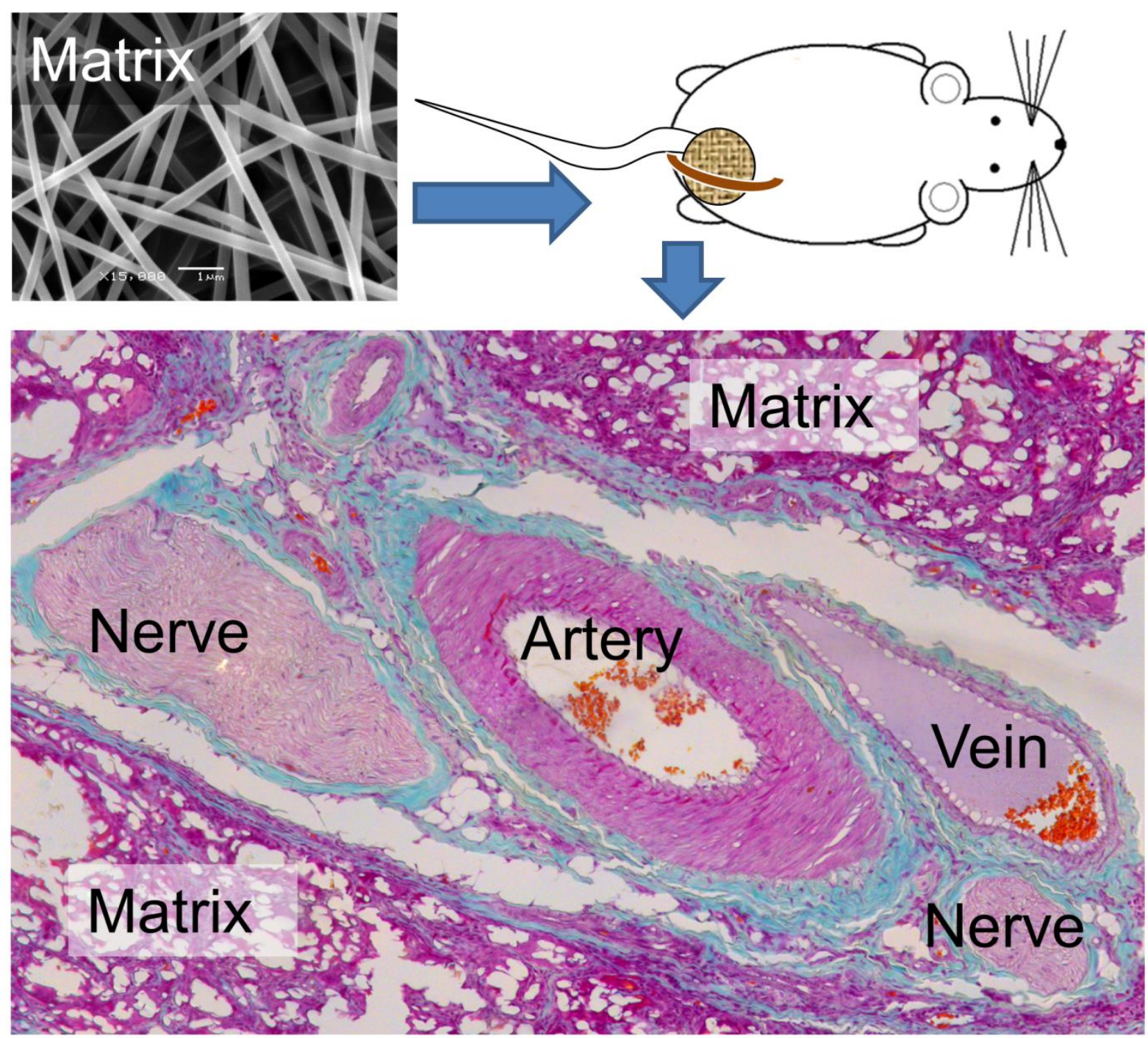


\section{WILEY-VCH}

\section{Supporting Information}

\section{Tissue Compatibility of SN-38-loaded Anticancer Nanofiber Matrices}

Alejandro Manzanares, Camilo A. Restrepo-Perdomo, Gaia Botteri, Helena Castillo-Ecija, Guillem Pascual-Pasto, Francesc Cano, Laura Garcia-Alvarez, Carles Monterrubio, Bonaventura Ruiz, Manuel Vazquez-Carrera, Mariona Suñol, Jaume Mora, Jose A. Tornero, Alejandro Sosnik, Angel M. Carcaboso*

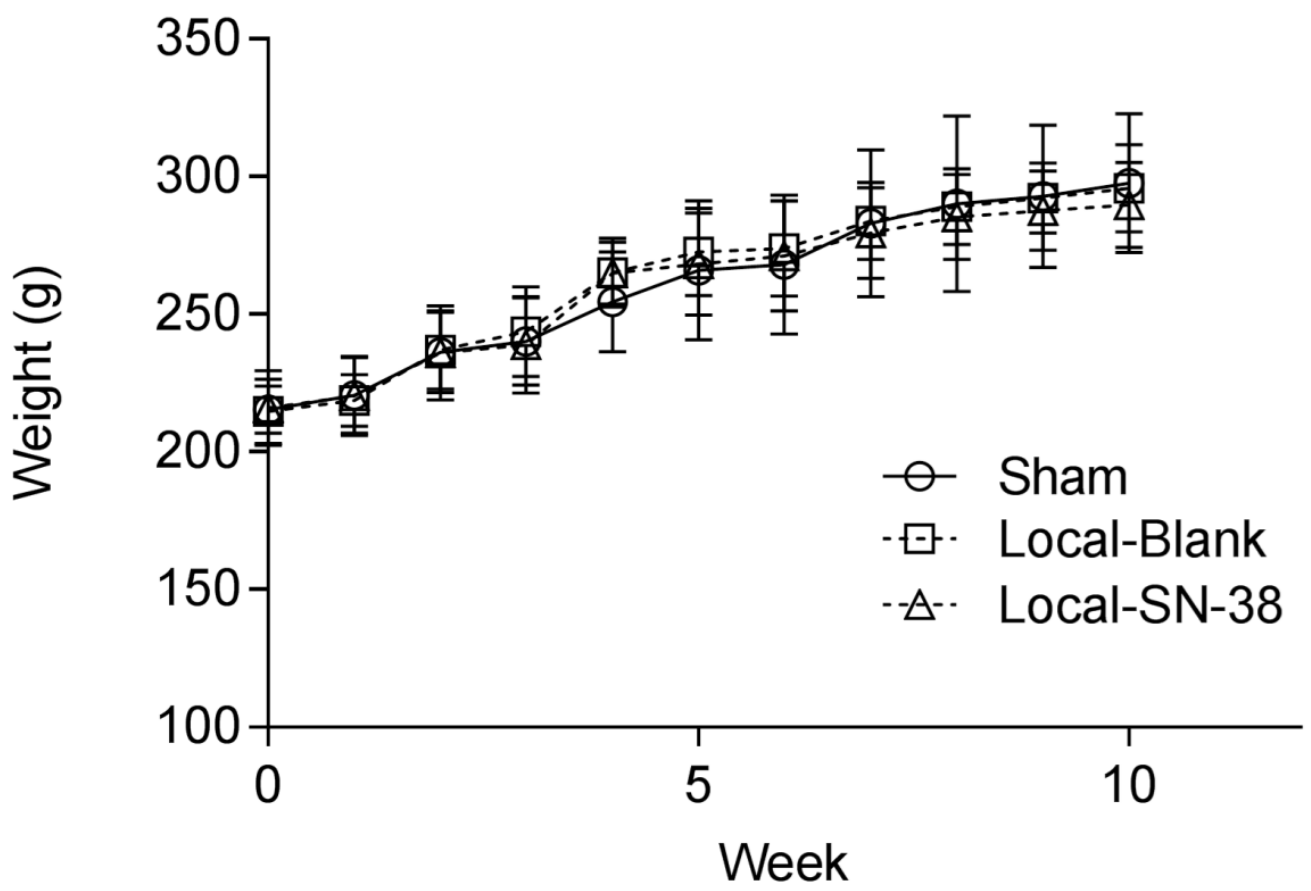

Supplemental Figure 1. Weight of the rats receiving each treatment (Sham, Local-Blank and Local-SN-38), represented from the day of the surgery $(t=0)$ and during a 10 week period. Means \pm SD of 9-18 animals are shown. 